\title{
SAFETY ZONE DETERMINATION FOR WIRELESS CELLULAR TOWER - A CASE STUDY FROM TANZANIA
}

\author{
Christina P.Nyakyi ${ }^{1}$, Salehe I. Mrutu ${ }^{2}$, Anael Sam ${ }^{3}$, Justinian Anatory ${ }^{4}$ \\ ${ }^{1}$ MSc. Student, ${ }^{2}$ PhD. Student, ${ }^{3}$ Senior Lecturer, The Nelson Mandela African Institute of Science and Technology, \\ Arusha,Tanzania.nyakyic @nm-aist.ac.tz,mrutui @nm-aist.ac.tz,anael.sam@nm-aist.ac.tz \\ ${ }^{4}$ Associate Professor, The University of Dodoma, Dodoma, Tanzania, anatory @ engineer.com
}

\begin{abstract}
Safety zone determination for wireless cellular towers has attracted attention from many researchers in the last decade. This is caused by the rapid growth of the wireless cellular industry which has led to the installation of towers even in the residential areas. There are many reports and ongoing researches regarding the biological and thermal effects of wireless cellular electromagnetic fields exposures to people. Cancer, hyperthermia, neural and behaviour effects of people exposed to these electromagnetic fields have been reported.

This motivates the research to determine safety zones from wireless cellular towers to assure safety to those living in the vicinity of these towers. A model for safety zone determination is developed. The model takes the received power at the object, power transmitted by the transmitter and gain of the transmitter as inputs to determine the safe distance from the radiation of a wireless cellular transmitter. The power density received by the object and its geographical location from the radiation source are measured using the selective radiation meter. Transmitted power and the gain of the transmitter together with the height of the tower were obtained from the respective wireless cellular network operator. Based on the geographical location of the object, the distance from the radiation source was calculated using the haversine formula. These inputs are then used to determine the safety zone based on the standards and guidelines developed by WHO and ICNIRP.
\end{abstract}

Keywords - Safety zone; Power density; wireless cellular tower; Exposure limits.

****

\section{INTRODUCTION}

The growth of the wireless cellular industry coupled with the proliferation of cellular mobile applications has led to more installation of wireless cellular transmission towers/base station antennas even in residential areas, schools, markets, hospitals, and other densely populated areas. This raises the public concern regarding the safety of population exposed to such networks with aggregated radiations[1].

Interaction of GSM electromagnetic fields and humans should include all particularities of human body which has very unusual electromagnetic properties values such as electric permittivity and electric conductivity[1].

These properties are not well known and depend on activity of person

- This material is an active material at cell scale

- Most cases, the problem is actually a coupled problem that is the thermal effect is one of the major effects and it is affected by the blood circulation

- The geometry is complex and generally environment of the human body has to be taken into account
Almost all guidelines and recommended limits on human exposure to GSM electromagnetic fields are given in terms of Specific Absorption Rate (SAR) defined by (1).

$$
S A R=\frac{\sigma\left|E^{2}\right|}{\rho_{m}}
$$

Where $\sigma$-Conductivity of body tissue,

$E$ - Root mean square of intensity of electrical field at considered point

$\rho m_{\text {-mass density of tissue at that point }}$

SAR, the time rate of RF energy absorbed per unit mass, is very difficult and complex to be measured in biological tissues; standards permit the use of reference levels of power flux density $[\mathrm{W} / \mathrm{m} 2]$ in free space. IEEE standard established the limits for electric and magnetic fields, so called maximum permissible exposure(MPE) and similarly ICNIRP standard defines reference limits for free-space incident fields as detailed in table 1 with safety limits exposure for public in 
some of the services. Getting together these limits SAR compliance should be ensured. So as a replacement for complex SAR measurements, for compliance assessments the above mentioned standards the simpler field measurements as power flux density are used[2].

In this paper we have presented results of measurements of field strength items of power flux density in the vicinity of base station antennas

Table 1: ICNIRP Safety Limits for public exposure

\begin{tabular}{|l|l|l|}
\hline $\begin{array}{l}\text { Service } \\
\text { Frequency }\end{array}$ & $\begin{array}{l}\text { ICNIRP } \\
\text { Safety limit } \\
\text { E-field [V/m] }\end{array}$ & $\begin{array}{l}\text { ICNIRP Safety } \\
\text { Limit Power } \\
\text { Density (W/m2) }\end{array}$ \\
\hline GSM 900 & 41.9 & 4.66 \\
\hline GSM 1800 & 58.4 & 9.05 \\
\hline WCDMA & 61 & 9.87 \\
\hline
\end{tabular}

\section{RELATED WORK}

The study done by Singh (2012), the exclusion zone (compliance distance) from GSM, CDMA, 3G/UMTS, and WiMAX antennas have been found at 7.30, 6.076, 7.436, and $6.861 \mathrm{~m}$, respectively are deduced. However, in this study values of EIRP which is transmitted and its gain as well as at what height of antenna should be installed is not defined [3].

The study titled Estimation of peak power density of electromagnetic radiation in near and far fields for $2 \mathrm{G}$ and $3 \mathrm{G}$ base station in Albania done by Cela et.al (2012), this study discussed on the safety distance from cellular base stations operating at $900 \mathrm{MHz}, 1800 \mathrm{MHz}$ and $2100 \mathrm{MHz}$ has been done by using a simplified theoretical way considering ideal conditions for wave propagation. The study also hasn't actual readings from the field as well as identify physical dimension for the surface even the time taken for capture the entire readings [4].

The study done by Kaur et.al, 2012 on the effect of permittivity and conductivity of tissue on SAR of electromagnetic radiations shows, how the Voltage Standing Wave Ratio (VSWR) and return loss from $900 \mathrm{MHz}$ communication frequency on simulated antenna for analyzing its effect in terms of variation in specific absorption rate (SAR) of EMF radiation in human tissue at different permittivity and conductivity has different effects accordingly. this study does not indicate whether the permittivity and conductivity are affected by distance variation from the source [5].

The study done by Kamo et al.(2011) shows; the relationship between theoretical values with exposure limits for both public and occupational from cellular base stations, FM, UHF and WiMAX antennas as well as suggest the possible safety distance from those antennas. The study based on estimated readings and not actual readings from the field [6].

Electromagnetic radiation from mobile phone base station at Gaza was the study aimed to highlight relevant international work and develop the computer tool which can simplify estimating and measuring EMF level in the city. The tool developed had to store the BTS parameters and coordinates in a database, and then it generates tables and maps that illustrate EMF level estimated theoretically. It doesn't define whether the level was on safety zone or unsafe distance rather than generate the maps and tables.[7].

The level of power density varies with the increase of gain as well as the power of transmitter was shown on the study done by Al-Bazzaz, 2008. In this study theoretical assessment of electric field strength and power density performed on locations tens of meters away from mobile phone base station antennas was presented. This study also doesn't show the safety zone [8].

\section{METHODOLOGY}

In this study we have done a field work on measuring power density at discrete levels by using Selective Radiation Hazard Meter (SRM) - Narda 3006 which has the ability to allocate the geographical location where the object located in terms of latitude and longitude as well as to quantify the value of power density. By having these two locations for source and object then the discrete distance was obtained by using the 'haversine' formula. This formula is more applicable in calculating the great-circle distance between the two points. The haversine formula is given by equation (2), (3) and (4).

$$
\begin{aligned}
& \text { Givenby, } a=\operatorname{Sin}^{2}\left(\frac{\Delta \theta}{2}\right)+\operatorname{Cos}\left(\theta_{1}\right) \cdot \operatorname{Cos}\left(\theta_{2}\right) \operatorname{Sin}^{2}\left(\frac{\Delta \lambda}{2}\right), \\
& c=2 \cdot a \tan ^{2}(\sqrt{a}, \sqrt{(1-a)}) \\
& d=\text { R.c. }
\end{aligned}
$$

Where; $\varphi$ is latitude, $\lambda$ is longitude, $\mathrm{R}$ is Earth's radius (mean radius $=6,371 \mathrm{~km})$. All angles are in radians

\subsection{Measurement of Power Density from Cellular}

\section{Towers}

Undertaking the measurements by SRM, the operating procedure is followed. The equipment was installed with software which has the ability of downloading the data as well as to identify the geographical location in terms of latitude and longitude with the help of building GPS. On setting the frequency span GSM $900 \mathrm{MHz}$ was on the range of $890 \mathrm{MHz}$ to 
$960 \mathrm{MHz}$, where GSM $1800 \mathrm{MHz}$ was on the span of $1790 \mathrm{MHz}$ up to $1880 \mathrm{MHz}$ the Resolution Bandwidth (RBW) was 17.5 and 450 respectively according to the manufacturer guidelines. The standard was observed for the Europe as per setting on the equipment.

On measuring technique the very high lobe should be detected so that the maximum power density can be obtained as shown on the figure 1.The detection of main lobe is done by visual and sweeping the measuring tool to detect the appropriate direction of the very high lobe.[9]

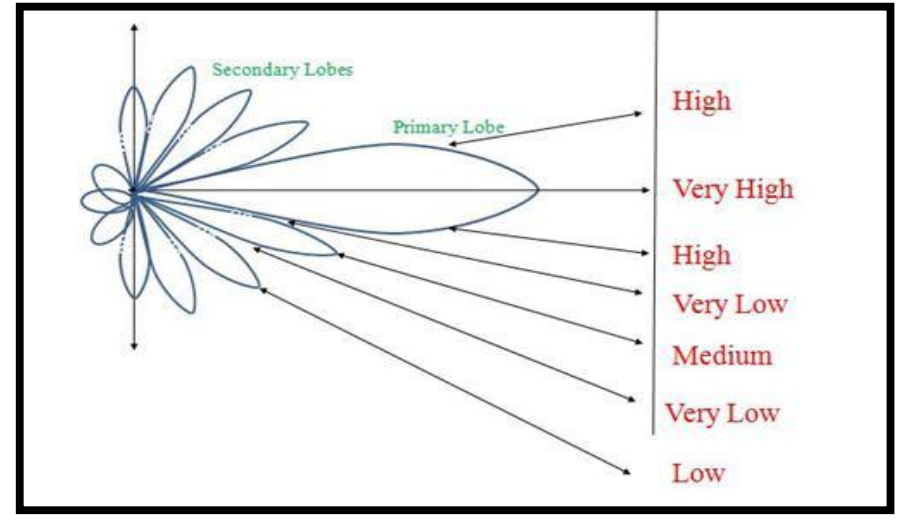

Figure 1: Radiation Pattern of Cell Tower Antennas

Table 2 and 3 shows the measurements obtained for GSM900 and GSM1800 antenna at the field area

Table 2: Mbauda Cellular tower, Tanzania - Actual data readings on 05/29/2013 at 10hrs

\begin{tabular}{|l|l|l|l|l|}
\hline \multirow{2}{*}{ Latitude $[\mathrm{S}]$} & \multirow{2}{*}{ Longitude[E] } & \multicolumn{2}{|l|}{ Power Density $\left[\mu \mathrm{W} / \mathrm{m}^{2}\right]$} & \multirow{2}{*}{ Distance $[\mathrm{m}]$} \\
\cline { 2 - 4 } & $900 \mathrm{MHz}$ & $1800 \mathrm{MHz}$ & \\
\hline $3^{\circ} 22^{\prime} 50.5^{\prime \prime}$ & $36^{\circ} 39^{\prime} 34.0^{\prime \prime}$ & 974.30 & 054.01 & 00.00 \\
\hline $3^{\circ} 22^{\prime} 50.8^{\prime \prime}$ & $36^{\circ} 39^{\prime} 34.0^{\prime \prime}$ & 936.52 & 281.43 & 09.27 \\
\hline $3^{\circ} 22^{\prime} 51.3^{\prime \prime}$ & $36^{\circ} 39^{\prime} 34.0^{\prime \prime}$ & 445.00 & 267.25 & 24.71 \\
\hline $3^{\circ} 22^{\prime} 51.6^{\prime \prime}$ & $36^{\circ} 39^{\prime} 34.0^{\prime \prime}$ & 004.06 & 049.59 & 33.98 \\
\hline $3^{\circ} 22^{\prime} 52.1^{\prime \prime}$ & $36^{\circ} 39^{\prime} 34.0^{\prime \prime}$ & 012.01 & 053.35 & 49.42 \\
\hline
\end{tabular}

Table 3: Mrombo Cellular tower, Tanzania - Actual data readings on 05/29/2013 at 14hrs

\begin{tabular}{|l|l|l|l|l|}
\hline \multirow{2}{*}{ Latitude $[\mathrm{S}]$} & \multirow{2}{*}{ Longitude $[\mathrm{E}]$} & \multicolumn{2}{|l|}{ Power Density $\left[\mu \mathrm{W} / \mathrm{m}^{2}\right]$} & \multirow{2}{*}{ Distance $[\mathrm{m}]$} \\
\cline { 2 - 4 } & & $900 \mathrm{MHz}$ & $1800 \mathrm{MHz}$ & \\
\hline $3^{\circ} 25^{\prime} 09.2^{\prime \prime}$ & $36^{\circ} 39^{\prime} 25.0^{\prime \prime}$ & 41.30 & 259.90 & 00.00 \\
\hline $3^{\circ} 25^{\prime} 09.5^{\prime \prime}$ & $36^{\circ} 39^{\prime} 24.8^{\prime \prime}$ & 64.00 & 148.60 & 09.27 \\
\hline $3^{\circ} 25^{\prime} 09.7^{\prime \prime}$ & $36^{\circ} 39^{\prime} 24.6^{\prime \prime}$ & 35.80 & 198.20 & 15.44 \\
\hline $3^{\circ} 25^{\prime} 10.0^{\prime \prime}$ & $36^{\circ} 39^{\prime} 24.4^{\prime \prime}$ & 59.30 & 146.50 & 24.71 \\
\hline $3^{\circ} 25^{\prime} 10.2^{\prime \prime}$ & $36^{\circ} 39^{\prime} 24.1^{\prime \prime}$ & 46.01 & 118.90 & 30.89 \\
\hline
\end{tabular}

The values in table 2 and 3 are very small compared to the limit exposure provided by the ICNIRP as shown on table 1 above. The measured value readings vary with respect to distance and time, which lead to stochastic readings.

\subsection{Derivation of Model Equations}

In this study we derive the power density received at destination in free space path loss for one and two antenna and generalize with n-antenna and consider the case when the height of object h0 is defined. We study the effect when the distance of object increases and the height changes.

\section{CASE 1: Single Tower}

Consider the case of single tower in a free space, a case common in rural/remote area.

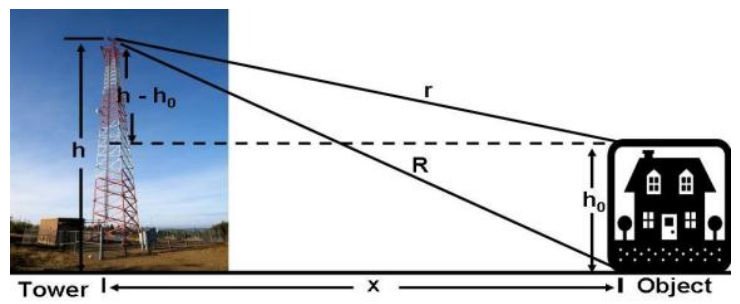

Figure 2: Single tower with an object. 
The power density at point on the ground at a distance, $\mathrm{x}$ metres from the tower is given by the equation:

$P_{d}=\frac{P_{t} G_{t}}{4 \pi R^{2}}$

Where; $P d$ means power density from cellular tower in $\mathrm{W} / \mathrm{m} 2$.

$p_{t}$ and $G_{t}$ are power and gain from transmitters in $\mathrm{dBm}$ and $\mathrm{dB}$ respectively and $\mathrm{R}$ the distance from transmission tower to object at ground level in metre. When the height of the tower $h$ in metre and the distance of the point $\mathrm{x}$ in metre from the tower are known, then we have;

$R^{2}=x^{2}+h^{2}$

Thus, we have;

$P_{d}=\frac{P_{t} G_{t}}{4 \pi\left(x^{2}+h^{2}\right)}$

Figure 4.3 shows the power density of $\mathrm{Pt}=16 \mathrm{dBm}$ and $20 \mathrm{dBm}$ with a gain $\mathrm{Gt}=17 \mathrm{~dB}$. These values were used because many service providers of cellular network use Pt in a range of $16 \mathrm{dBm}$ to $20 \mathrm{dBm}$

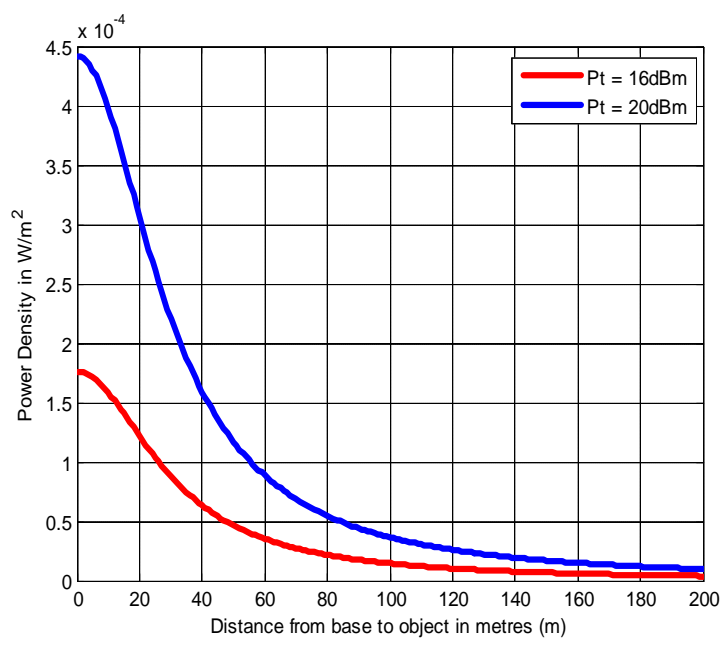

Figure 2: Power density versus distance of a point for $\mathrm{Pt}=$ $16 \mathrm{dBm}, 20 \mathrm{dBm}$ and a gain $\mathrm{Gt}=17 \mathrm{~dB}$

The graph shows that power density decrease with the increase in distance of a point from the tower, and at some point the power density attains a constant minimum value.
If the equation (5) is modified to consider the height, h0, of an object (like a house or human), then power density at the top of the house is given by:

$P d=\frac{P_{t} G_{t}}{4 \pi r^{2}}$

But $r^{2}=x^{2}+\left(h-h_{0}\right)^{2}$

Then equation (8) become;

$P_{d}=\frac{P_{t} G_{t}}{4 \pi\left(x^{2}+\left(h-h_{o}\right)^{2}\right)}$

Figure 4. Shows the variation of power density at the top of an object of 3 metres height for antenna with $\mathrm{Pt}=16 \mathrm{dBm}$, $20 \mathrm{dBm}$, and $25 \mathrm{dBm}$. Field data for GSM900 and GSM1800 has been plotted together to enable comparison with theoretical values. The graph shows that power densities from the field were less than the theoretical power densities produced by an antenna of $\mathrm{Pt}=25 \mathrm{dBm}$.

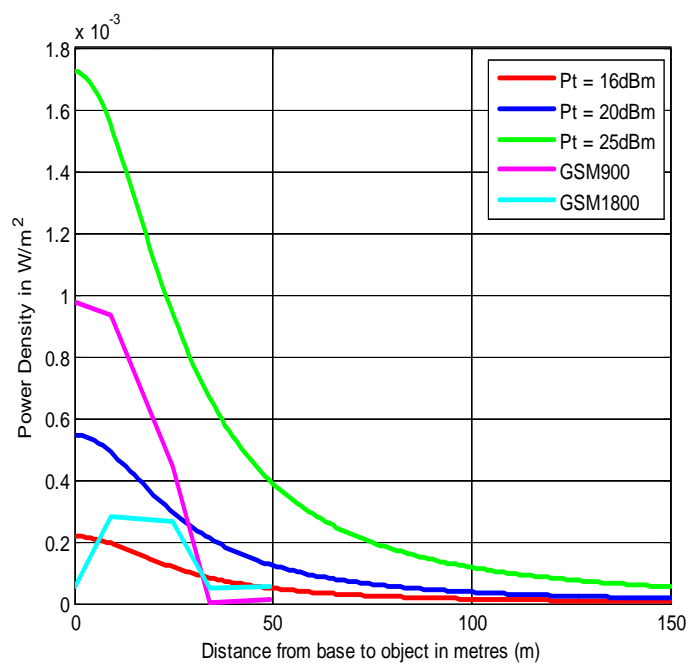

Figure 3: Power Density with fixed height of object ho $=3 \mathrm{~m}$ in various $\mathrm{Pt}$

To compute the total power density absorbed by an object of height h0, we use the idea of calculus, and show that the total power density is given by

Total Power Density =

$\int_{0}^{h_{O}} P_{d}=\frac{P_{t} G_{t}}{4 \pi}\left[\arctan \left(\frac{h}{x}\right)-\arctan \left(\frac{h-h_{0}}{x}\right)\right]$ 
Remember that this formula is applicable only when $\mathrm{h} 0$ is defined otherwise the total power for $\mathrm{h} 0=0$ is computed from equation (5).

Figure 5. Shows the total power density at the top of various object heights from $3 \mathrm{~m}$ to $10 \mathrm{~m}$. It can be seen that total power density increases with the height of an object

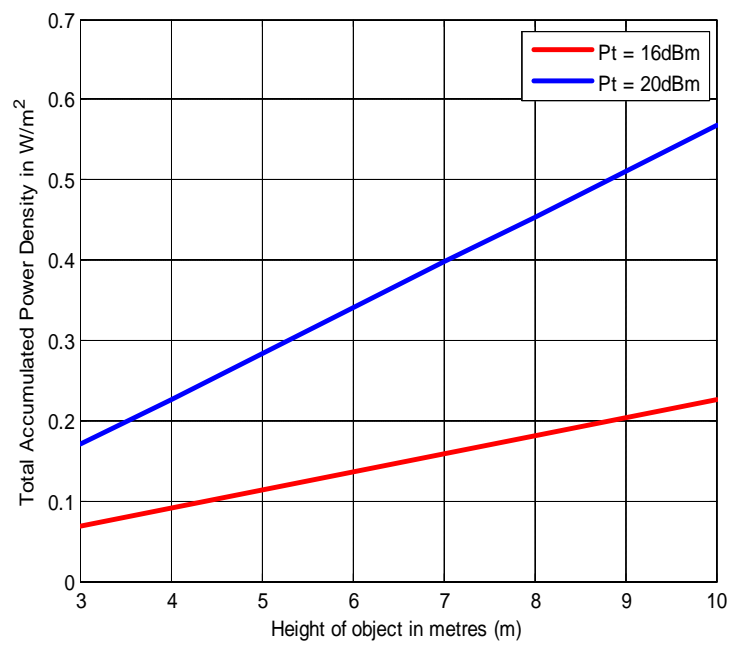

Figure 4: Total Power Density for object with height from $\mathrm{h} 0=3 \mathrm{~m}$ to $10 \mathrm{~m}$

\section{CASE 2: Two Towers}

Consider two towers that generate and transmit power at P1 and $\mathrm{P} 2$. Let the respective height of towers be $\mathrm{h} 1$ and $\mathrm{h} 2$ and $\mathrm{x} 1$ and $\mathrm{x} 2$ be the horizontal distance of the object from the two towers respectively. The power density at a particular point on the ground will be the sum of the power densities from the two antennas.

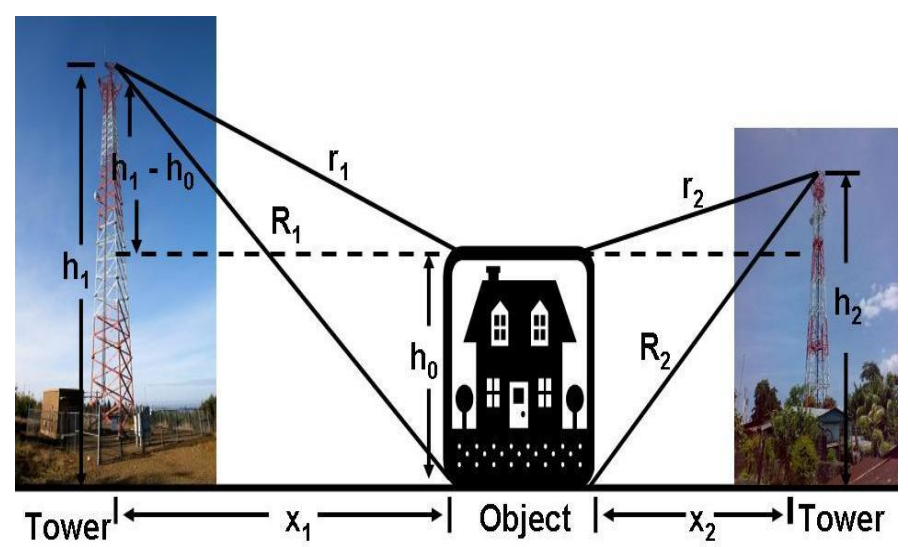

Figure 5: Power Density to an object from two towersFrom Pythagoras theorem, we have

$$
\begin{aligned}
& R_{1}^{2}=h_{1}^{2}+x_{1}^{2} \\
& R_{2}^{2}=h_{2}^{2}+x_{2}^{2}
\end{aligned}
$$

The power density for each antenna from the two towers is given by

$$
\begin{gathered}
P_{d, 1}=\frac{P_{1} G_{1}}{4 \pi R_{1}^{2}} \\
P_{d, 2}=\frac{P_{2} G_{2}}{4 \pi R_{2}^{2}}
\end{gathered}
$$

By substituting equation (12) and (13) into equation (14) and (15) then it becomes

$$
\begin{aligned}
& P_{d, 1}=\frac{P_{1} G_{1}}{4 \pi\left(h_{1}^{2}+x_{1}^{2}\right)} \\
& P_{d, 2}=\frac{P_{2} G_{2}}{4 \pi\left(h_{2}^{2}+x_{2}^{2}\right)}
\end{aligned}
$$

The average power density at a point from the two antennas is given by

$$
P_{d}=P_{d, 1}+P_{d, 2}=\frac{1}{4 \pi}\left[\left(\frac{P_{1} G_{1}}{h_{1}^{2}+x_{1}^{2}}\right)+\left(\frac{P_{2} G_{2}}{h_{2}^{2}+x_{2}^{2}}\right)\right]
$$

Figure 7. Shows that power density depends on the distance of an object from the antenna. That is, power density decreases as the density increases

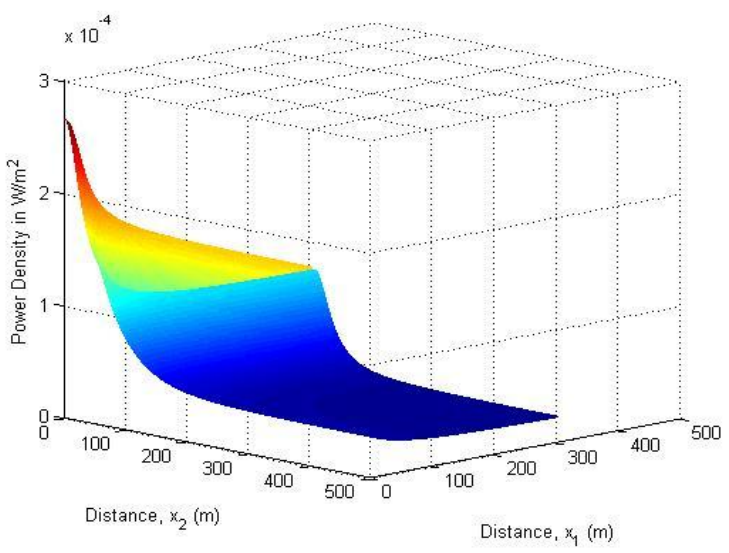

Figure 6: Graph of Power Density at a object from two antennaWhen the height of object is considered then the expression (18) is derived as shown on equation (19) and its relation is illustrated in the graph figure 8 . 
$P_{d}=P_{d, 1}+P_{d, 2}=\frac{1}{4 \pi}\left[\left(\frac{P_{1} G_{1}}{\left(h_{1}-h_{0}\right)^{2}+x_{1}^{2}}\right)+\left(\frac{P_{2} G_{2}}{\left(h_{2}-h_{0}\right)^{2}+x_{2}^{2}}\right)\right]$

Figure 8 shows the variation of power density at the top of an object of height $3 \mathrm{~m}$ situated at a distance $\mathrm{x} 1$ and $\mathrm{x} 2$ from the two antennas of height $h 1$ and $h 2$ respectively.

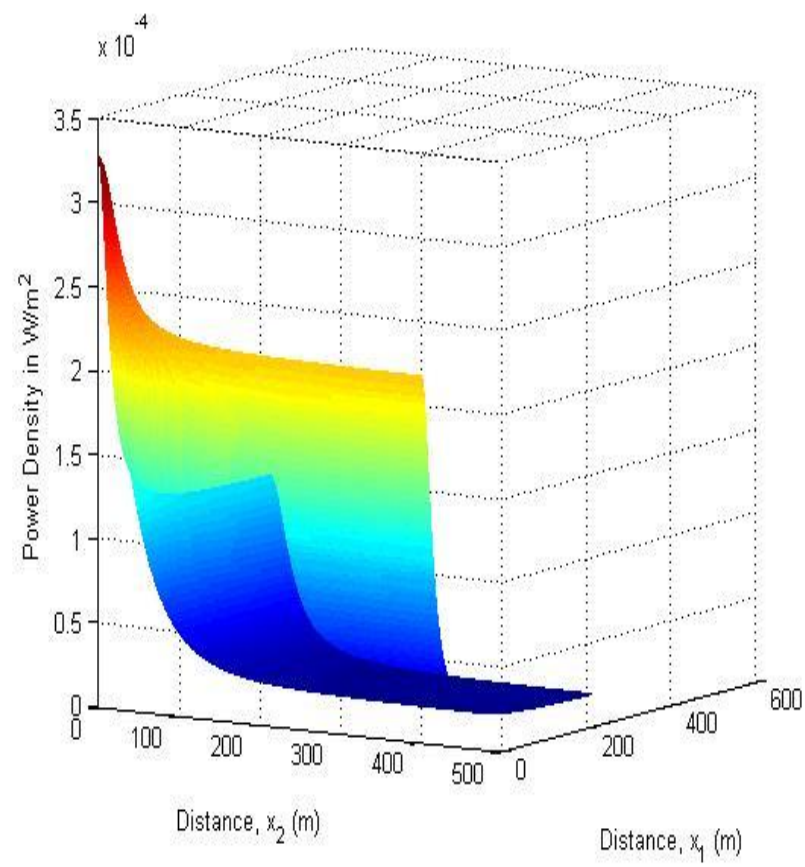

Figure 7: Power Density from two towers for an object at a height ho $=3 \mathrm{~m}$

\section{CASE 3: For $n$ towers}

$P_{d, i}=\sum_{i=1}^{n} \frac{P_{i} G_{i}}{4 \pi R_{i}^{2}}$

For $\quad R_{i}^{2}=x_{i}^{2}+h_{i}^{2}$

Then, $\quad P d, i=\sum_{i=1}^{n} \frac{P_{i} G_{i}}{4 \pi\left(x_{i}^{2}+h_{i}^{2}\right)}$

If height of object $h_{0}$ is considered

Therefore;

$P d, i=\sum_{i=1}^{n} \frac{P_{i} G_{i}}{4 \pi\left(x_{i}^{2}+\left(h_{i}-h_{0}\right)^{2}\right)}$

$$
P_{d, i}=\frac{1}{4 \pi} \sum_{i=1}^{n} \frac{P_{i} G_{i}}{\left(x_{i}^{2}+\left(h_{i}-h_{0}\right)^{2}\right)}
$$

Note: The equation (24) is a general expression which can be used to determine the power density at any point for an object with height 0 to h0 provided that power transmitted and the gains of antenna as well as the distance from the transmitter are known.

\subsection{Computation and Validation of safety zone}

There are a number of national and international regulations standards and recommendations dealing with electromagnetic exposure in the radio frequency range. The limits are generally very similar and usually based on recommendation from the World Health Organization (WHO) and the International Commission on Non-Ionizing Radiation Protection (ICNIRP) guidelines. It is shows that the limits have been set with a wide margin in order to protect people from any known negative health effects of both short and long term exposure to electromagnetic field. Basic restrictions on exposure are provided for both occupational exposure and public exposure.

The standard posed by ICNIRP guidance for public exposure limits is $9.2 \mathrm{~W} / \mathrm{m}^{2}$ for GSM $1800 \mathrm{MHz}$ and $4.7 \mathrm{~W} / \mathrm{m}^{2}$ for GSM $900 \mathrm{MHz}$. However, these limits can be tolerable if the person is exposed for few seconds and not for permanent exposure [10].

Consider a case of a human lying on the bed of $2 \mathrm{~m}^{2}$ the hip or height made by the body taken to be negligible. Then, the power absorbed is given by exposure limits times the surface area.

For GSM 1800 power density;

$P_{d}=2 m^{2} \times 9.2 \mathrm{~W} / m^{2}=18.4 \mathrm{~W}$

For GSM 900 power density;

$$
P_{d}=2 m^{2} \times 4.7 \mathrm{~W} / m^{2}=9.4 \mathrm{~W}
$$

If time is considered then power absorbed For 30min. exposure in GSM 1800;

$$
P_{d}=18.4 W \times(30 \times 60) \mathrm{sec}=33,120 \text { Joule }
$$

For 30min. exposure in GSM 900;

$$
P_{d}=9.4 \mathrm{~W} \times(30 \times 60) \mathrm{sec}=16,920 \text { Joule }
$$

If the exposure provided is compared with the exposure from the microwave cooker of $500 \mathrm{~W}$ then; 
For GSM 1800 the exposure will be $=$ $33120 \mathrm{~W} \cdot \mathrm{sec} / 500 \mathrm{~W}=670 \mathrm{sec}$

While the exposure for GSM 900 will be $=$ $16920 \mathrm{~W} . \mathrm{sec} / 500 \mathrm{~W}=33.84 \mathrm{sec}$
This exposure time is high for a person who is exposed for the long time. We need to look for the minimum distance for tolerable exposure. To do this we apply the standard given by EMF-Exposure-Guidelines-For-Sleeping-Areas[11] which recommend the maximum exposure of $10 \mu \mathrm{W} / \mathrm{m}^{2}$ to be of less concern as shown on the table below.

Table 4: Exposure guidelines for sleeping area

\begin{tabular}{|l|l|l|l|l|}
\hline $\begin{array}{l}\text { Power density in } \\
\text { microwatt }\end{array}$ & No Concern & Slight Concern & Severe Concern & $\begin{array}{l}\text { Extreme } \\
\text { Concern }\end{array}$ \\
\hline per square meter $\mu \mathrm{W} / \mathrm{m}^{2}$ & $<0.1$ & $0.1-10$ & $10-1000$ & $>1000$ \\
\hline per square $\mathrm{cm} \mu \mathrm{W} / \mathrm{cm}^{2}$ & $<0.000,01$ & $0.000,01-0.001$ & $0.001-0.1$ & $>0.1$ \\
\hline
\end{tabular}

Figure 9; shows the minimum distance where an object can live with less concern of exposure. The distance is obtained by the point at which the graph for power densities meets the line $\mathrm{Pd}=10 \mu \mathrm{W} / \mathrm{m}^{2}$ shown by black line above zero power density. This distance is the safety distance to live. The safety zone depends on the power transmitted by the antenna [11].

Thus for the power transmitted; $P_{t}=16 \mathrm{dBm}$ is $120 \mathrm{~m}$ And for power transmitted; $P_{t}=20 \mathrm{dBm}$ is $190 \mathrm{~m}$ as shown on the figure 9 .

Therefore more the power of transmitter the far the safety zone occur.

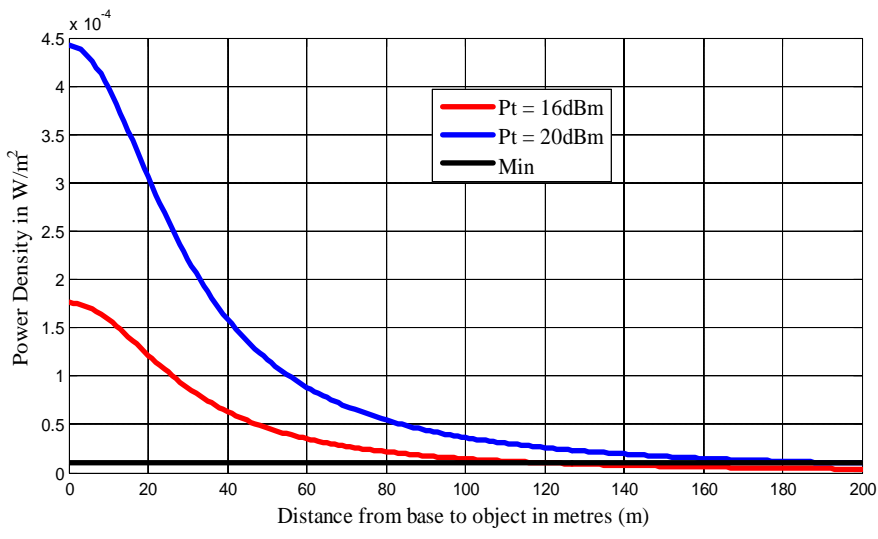

Figure 8: Graph of Power densities versus distance with safety zone defined.

\section{FINDINGS, RESULTS AND CONCLUSIONS}

\subsection{Findings Regard the Measurements}

To gain understanding of the power densities at different point from the antenna, measurement of power density were made at discrete distances from the transmission towers. Due to geographical limitations, geographical locations were taken and later converted to distances as it has been explained in Section 3 subsection A. The results show that the power densities depend on the distance from the antenna. That is, the longer the distance the smaller the power density and that the power density is maximum at the tower. The results also show that the power density at a point from an antenna depended on the application. That it, the power density from a GSM900 application was different from the GSM1800 application.

Numerical analysis reveals that the power received by the object varies directly proportional with the power transmitted by the source and inversely proportional with its square distance from the source. The greater the power transmitted, the longer the distance to the safety zone, and hence it becomes severe to live near the source.

\subsection{Findings Regard the Safety Zone}

To develop a model for cellular tower radiations several parameters were considered including the power transmitted by an antenna, the gain of an antenna, the allowable exposure for both GSM900 and GSM1800 and the surface area occupied by an object. The results show that the safety zone will much depend on the power transmitted by the antenna given the same antenna gain. From our study the safety zone for transmitted power of $16 \mathrm{dBm}$ was $120 \mathrm{~m}$ and for $20 \mathrm{dBm}$ was $190 \mathrm{~m}$ for a gain of antenna of $17 \mathrm{~dB}$,

To validate the model measurement taken from the field were plotted together with the theoretical values. The data for GSM900 were below the graph corresponding to $\mathrm{Pt}=25 \mathrm{dBm}$ and those from GSM1800 were below the graph corresponding to $\mathrm{Pt}=20 \mathrm{dBm}$.

Furthermore, the results show that all the measurements taken within $50 \mathrm{~m}$ from the antenna in the field were above the minimum exposure of $10 \mu \mathrm{W} / \mathrm{m}^{2}$ for sleeping areas. 
The results obtained in this study for safety zone are far greater than those obtained by Kamo et al (2012) which were between 12.9 to 46.3 meters from antenna for GSM900, 1800.respectively, the difference is due to exposure limits used where Kamo used $9 \mathrm{~W} / \mathrm{m}^{2}$ and $4.5 \mathrm{~W} / \mathrm{m}^{2}$ exposure limits from ICNIRP guidelines recommendation [6].

\subsection{Results and Conclusions}

The results regarding the safety zone shows that the safety zone depend on the power transmitted by the antenna for the same antenna gain. The safety zone for transmitted power of $16 \mathrm{dBm}$ was $120 \mathrm{~m}$ and for $20 \mathrm{dBm}$ was $190 \mathrm{~m}$ for a gain of antenna of $17 \mathrm{~dB}$ with the fixed height of antenna $30 \mathrm{~m}$ above the ground. All field measurements taken within $50 \mathrm{~m}$ from the antenna in the field were above the minimum exposure of $10 \mu \mathrm{W} / \mathrm{m}^{2}$ for sleeping areas.

The measurements of power densities at the field and the model has been presented to give an estimate of the safety zone for people living in close vicinity to wireless cellular towers. Different analyses have been carried out before estimating the safety zone. Results have shown that safety zone depends on the power transmitted by the antenna. However, for a power of $16 \mathrm{dBm}$ taken to be the smallest, the safety zone was $120 \mathrm{~m}$ from the tower. This call for a concern for people living in the close vicinity and respective authorities should ensure that people reside far from the tower by $120 \mathrm{~m}$ or more depending on the power transmitted to avoid severe health effect.

\section{REFERENCES}

[1] L. Nicolas, et al., "Interactions between electromagnetic field and biological tissues: Questions, some answers and future trends," International Compumag Society Newsletter, vol. 10, pp. 4-9, 2003.

[2] L. A. Mimoza Ibrani, Enver Hamiti,Ruzhdi Sefa, "Exposure assessment in the vicinity of $900 \mathrm{MHz}$ GSM base station antenna," in The 11th WSEAS International Conference on COMMUNICATIONS, Agios Nikolaos, Crete Island ,Greece., 2007.

[3] R. Singh, "Assessment of electromagnetic radiation from base station antennas," Indian Journal of Radio \& Space Physics, vol. 41, pp. 557-565, 2012.

[4] A. L. Sanije Cela, Bexhet Kamo, Aleksander Biberaj and Rozeta Miho Mitrushi, "Estimation of Simultaneous Exposure to Electromagnetic Radiation of $2 \mathrm{G}$ and $3 \mathrm{G}$ Base Stations in Albania," Journal of Communication and Computer vol. 9 pp. 1142-1146, 2012.

[5] E. V. T. E. H. M. Er.Amarjeet Kaur, V.K.Lamba,Er.Nitesh Kumar,Sanjay Sharma, , "Effect of permitivity and Conductivity of Tishue on Specific Absorption Rate of Electromagnetic Radiations," International Journal of Innovative Technology and Exploring Engineering (IJITEE) vol. 1, 2012.
[6] R. M. Bexhet Kamo, Vladi Kolici,Sanie Cela, Algenti Lala, "Estimation of peak power density in the vicinity of cellular base stations, FM,UHF and WiMAX antennas," International Journal of Engineering \& Technology IJETIJENS, vol. Vol:11, 2011.

[7] M. Abdelati, "Electromagnetic Radiation from Mobile Phone Base Stations at Gaza," At Islamic University of Gaza (Natural Sciences Series), vol. Vol.13, pp. p129-146, 2005.

[8] S. H. S. Al-Bazzaz, "Theoretical Estimation of Power Density Levels around Mobile Telephone Base Stations," Journal of Science \& Technology, vol. 13, 2008.

[9] M. K. T. S. A. Kumar, "Effects of Mobile Tower Radiations \& Case Studies from different Countries Pertaining the Issue," International Journal of Applied Engineering Research, vol. 7, 2012

[10] ICNIRP, "Guidelines for limiting exposure to timevarying electric, magnetic fields (up to $300 \mathrm{GHz}$ )," ed. Health Physics Society, 1998, pp. 494-522.

[11] G. Abdel-Rassoul, et al., "Neurobehavioral effects among inhabitants around mobile phone base stations," Neurotoxicology, vol. 28, pp. 434-440, 2007. 